Rheumatology (ACR), and European League Against Rheumatism (EULAR). ${ }^{1,2,3}$ The core sets of measures developed include assessments and composite indices incorporating use of patient-reported outcomes (PROs) and clinical measures and clinicians' assessments to quantify disease activity over time. ${ }^{2}$ PROs are important indicators of disease activity and variability, and they are increasingly used to evaluate treatment effectiveness. Little is known about PROs that patients with rheumatic conditions find most important to convey their experience with their condition and its treatment.

Objectives: To examine PROs selected by patients with rheumatic conditions in the ArthritisPower registry to identify symptoms they found most important to track digitally.

Methods: Adult US patients within the ArthritisPower registry with rheumatoid arthritis (RA), psoriatic arthritis (PsA), ankylosing spondylitis (AS), systemic lupus erythematosus (SLE), osteoporosis (OP), osteoarthritis (OA), and fibromyalgia syndrome (FMS) were invited via email to participate in this study. Enrolled participants (pts) were prompted to select $\leq 10$ PRO symptom measures they felt were important to track for their condition at baseline via the ArthritisPower app. At 3 subsequent time points (Month [m] 1, m2, m3), pts were given the option to continue tracking their previously selected PRO measures or to add, remove and/or select different measures. At m3, pts completed an exit survey to prioritize $\leq 5$ measures from all measures selected during study participation and to specify other symptoms not available that they would have wanted to track. Measures were rank-ordered based on number of pts rating the item as their 1st, 2nd, 3rd, 4 th or 5 th choice and weighted by multiplying the rank number by its inverse for a single, weighted summary score for each measure. Values were summed across all pts to produce a summary score for each measure.

Results: Among pts who completed initial selection of PRO assessments at baseline ( $\mathrm{N}=253$ ), 184 pts confirmed or changed PRO selections across m1-3. Mean (SD) age of pts was 55.7 (9.2) yrs, 89.3\% female, 91.3\% White, mean disease duration of $11.6(10.6) \mathrm{yrs}$. The majority $(64.8 \%)$ self-reported OA, followed by RA (48.6\%), FMS (40.3\%), PsA (26.1\%), OP (21.0\%), AS (15.8\%) and SLE $(5.9 \%)$, not mutually exclusive, and were similar to the overall ArthritisPower population. The average number of instruments (SD) selected for baseline completion was 7.0 (2.5), $7.1(2.4)$ at $\mathrm{m} 1,7.2(2.4)$ at $\mathrm{m} 2$, and $7.0(2.5)$ at $\mathrm{m} 3$. The top 5 PROs ranked by pts overall as most important (weighted summary score) for tracking were Fatigue (71), Physical Function (58), Pain Intensity (50), Pain Interference (49), Duration of Morning Joint Stiffness (41) (Figure 1). Fatigue, Physical Function, and Pain were consistently in the top 5 across diseases while Depression was more frequent among pts with OA, AS and FMS. Pts' PRO selections showed stability over time except for the RA Flare measure which decreased from $70.5 \%$ of RA pts at baseline to $13.6 \%$ at $\mathrm{m} 3$.

Conclusion: The symptoms prioritized by pts included fatigue, physical function, pain, and joint stiffness. Pts' choices were consistent over time. These findings provide insights into symptoms rheumatology patients find most important and will be useful to inform design of future patient-centric clinical trials and realworld evidence generation.

References:

[1] Boers M, et al. J Rheumatol Suppl. 1994;41:86-89.

[2] Felson DT, et al. Arthritis Rheum. 1993;36:729-740.

[3] Tugwell P, et al. J Rheumatol. 1993;20:555-556.

Figure 1. Overall Participant Ranking of PRO Selections (weighted summary score) at Study Conclusion $(\mathrm{m} 3)^{*}$

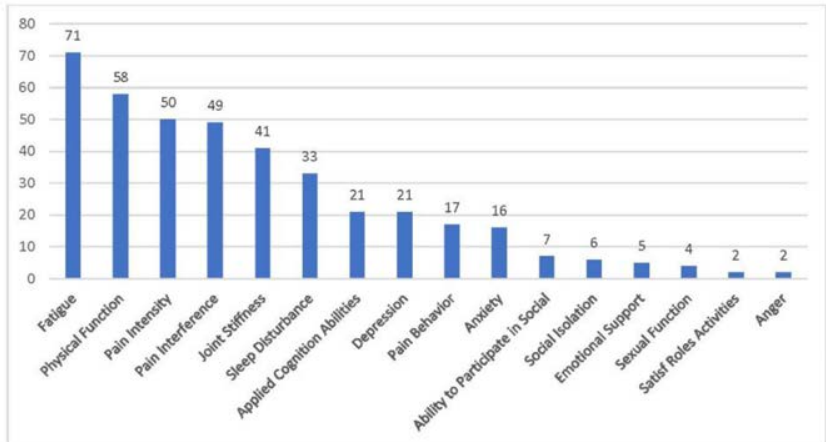

"Considering all PROs selected during the 3-month study, participants selected their first through fifth choice by importance only those participants who completed the 3 months of the study $(\mathrm{N}=184$ ). Weighted summary scores were generated based

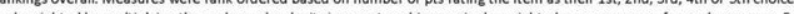
ind weighted by muttiplying the rank number by is inverse to achieve a single weighted summary score for eath

Disclosure of Interests: W. Benjamin Nowell: None declared, Carol L. Kannowski Shareholder of: Eli Lilly and Company, Employee of: Eli Lilly and Company, Kelly Gavigan: None declared, Zhihong Cai Shareholder of: Eli Lilly and
Company, Employee of: Eli Lilly and Company, Anabela Cardoso Shareholder of: Eli Lilly and Company, Employee of: Eli Lilly and Company, Theresa Hunter Shareholder of: Eli Lilly and Company, Employee of: Eli Lilly and Company, Shilpa Venkatachalam: None declared, Julie Birt Shareholder of: Eli Lilly and Company, Employee of: Eli Lilly and Company, Jennifer Workman Shareholde of: Eli Lilly and Company, Employee of: Eli Lilly and Company, Jeffrey Curtis Grant/research support from: AbbVie, Amgen, Bristol-Myers Squibb, Corrona Janssen, Lilly, Myriad, Pfizer, Regeneron, Roche, UCB, Consultant of: AbbVie, Amgen, Bristol-Myers Squibb, Corrona, Janssen, Lilly, Myriad, Pfizer, Regeneron, Roche, UCB

DOI: 10.1136/annrheumdis-2020-eular.1016

\section{PARE0027 PATIENT PERSPECTIVE ON INTRA-ARTICULAR THERAPIES IN RMDS: RESULTS FROM A EUROPEAN SURVEY}

I. Pitsillidou' ${ }^{1}$, J. De la Torre-Aboki ${ }^{2}$, J. Uson Jaeger ${ }^{3}$, E. Naredo ${ }^{4}$, L. Terslev ${ }^{5}$ M. Boesen ${ }^{6}$, H. Pandit ${ }^{7}$, I. Möller ${ }^{8}$, M. A. D'agostino ${ }^{9}$, W. U. Kampen ${ }^{10}$,

T. O'neill ${ }^{11}$, M. Doherty ${ }^{12}$, F. Berenbaum ${ }^{13}$, V. Vardanyan ${ }^{14}$, E. Nikiphorou $^{15}$ S. C. Rodriguez-García ${ }^{16}$, R. Castellanos-Moreira ${ }^{17}$, L. Carmona ${ }^{18} .{ }^{1}$ Cyprus League Against Rheumatism, Nicosia, Cyprus; ${ }^{2}$ Hospital general universitari d'Alacant, Alacant, Spain; ${ }^{3}$ Hospital Universitario de Móstoles, Móstoles, Spain; ${ }^{4}$ Hospital Universitario Fundación Jiménez Díaz, Madrid, Spain; ${ }^{5}$ Rigshospitalet, København, Denmark; ${ }^{6}$ Bispebjerg and Frederiksberg Hospital, Copenhagen, Denmark; ${ }^{7}$ University of Leeds, Leeds, United Kingdom; ${ }^{8}$ Institut Poal de Reumatologia, Barcelona, Spain; ${ }^{9}$ APHP-Université Paris-Saclay Versailles, Inserm, Boulogne-Billancourt, France; ${ }^{10}$ Rad. Allianz, Nuklearmedizin Spitalerhof, Hamburg, Germany; ${ }^{11}$ Manchester University, Manchester, United Kingdom; ${ }^{12}$ University of Nottingham, Nottingham, United Kingdom; ${ }^{13}$ AP-HP Sorbonne Université, Inserm, Paris, France; ${ }^{14}$ Mikayelyan University Hospital, Yerevan, Armenia; ${ }^{15}$ King's College, London, United Kingdom; ${ }^{16} \mathrm{Hospital}$ Universitario de la Princesa, Madrid, Spain; ${ }^{17}$ Hospital Clínic de Barcelona, Barcelona, Spain: ${ }^{18}$ InMusc, Madrid, Spain

Background: Intra-articular therapy (IAT) is routinely used in rheumatic and musculoskeletal diseases (RMDs). In order to improve the effectiveness and safety of IAT, it is essential to understand patients' perceptions and needs.

Objectives: To assess the perspective of persons who have experienced IAT, including perceptions on benefits and safety.

Methods: A steering committee (including a patient research partner) prepared a 44-item questionnaire based on the information needs of a Taskforce on IAT in adult patients with RMDs. The questionnaire was translated into 11 languages and disseminated via EULAR PARE associations and social media. Persons who had experienced at least two IAT procedures were eligible for the survey Descriptive statistics were used to summarise results as well as inductive codification of open-ended questions.

Results: The survey was answered by 200 individuals diagnosed with rheumatoid arthritis $(66 \%)$, osteoarthritis $(21 \%)$, spondyloarthritis $(10 \%)$, psoriatic arthritis $(9 \%)$, and others $(16 \%)$. The mean number of IATs received was 7 (SD 8$)$, mainly in the knee $(66 \%)$, shoulder $(42 \%)$, and wrist $(28 \%)$, and primarily with corticosteroids $(83 \%)$ or hyaluronic acid $(16 \%)$. Twenty-seven percent had not been informed about benefits or potential complications of IAT, and $73 \%$ had not been asked whether they wanted local anaesthetic. Consent was deemed necessary by $82(41 \%)$. Most (65\%) had never received an ultrasound (US)-guided injection, and of those who had experienced blinded and guided injections, 42 (63\%) preferred US-guided because of increased perceived accuracy and confidence in the procedure. Only 50\% reported a clear benefit of IAT, mainly in terms of reduced pain and increased joint mobility, but also perceived reduced inflammation, with effect from immediate to 36 hours or even 3 weeks post-injection, and that lasted from as little as less than one week to years. Regarding safety, 40 (20\%) had experienced some complications from IAT, including but not limited to increased pain, impaired mobility, rashes, or swelling.

Finally, the respondents suggested improvements in the procedure, including: (1) wider availability; (2) less painful procedures; (3) greater efficacy, faster and longer-lasting; (4) fewer side effects; (5) a clear diagnosis beforehand; (6) better shared decision-making, including better information; (7) follow-up, (8) better accuracy; and (9) more expertise.

Conclusion: The survey has identified gaps in the IAT procedures, such as a need for clearer information. Patients perceive IAT as relatively safe, though painful, and with varying effect. Suggestions for improving the procedure, including more expertise, should be relayed to professionals and relevant organisations.

Acknowledgments: Eular Taskforce grant CL109

Disclosure of Interests: IRENE Pitsillidou: None declared, Jenny de la TorreAboki: None declared, Jacqueline Uson Jaeger: None declared, Esperanza Naredo: None declared, Lene Terslev: None declared, Mikael Boesen Consultant of: AbbVie, AstraZeneca, Eli Lilly, Esaote, Glenmark, Novartis, Pfizer, 
UCB, Paid instructor for: IAG, Image Analysis Group, AbbVie, Eli Lilly, AstraZeneca, esaote, Glenmark, Novartis, Pfizer, UCB (scientific advisor)., Speakers bureau: Eli Lilly, Esaote, Novartis, Pfizer, UCB, Hemant Pandit Grant/ research support from: Glaxo Smith Kline (GSK) for work on Diclofenac Gel, Speakers bureau: Bristol Myers Squibb for teaching their employees about hip and knee replacement, Ingrid Möller: None declared, Maria Antonietta D'Agostino Consultant of: AbbVie, BMS, Novartis, and Roche, Speakers bureau: AbbVie, BMS, Novartis, and Roche, Willm Uwe Kampen: None declared, Terence O'Neill: None declared, Michael Doherty Grant/research support from: AstraZeneca funded the Nottingham Sons of Gout study, Consultant of: Advisory borads on gout for Grunenthal and Mallinckrodt, Francis Berenbaum Grant/research support from: TRB Chemedica (through institution), MSD (through institution), Pfizer (through institution), Consultant of: Novartis, MSD, Pfizer, Lilly, UCB, Abbvie, Roche, Servier, Sanofi-Aventis, Flexion Therapeutics, Expanscience, GSK, Biogen, Nordic, Sandoz, Regeneron, Gilead, Bone Therapeutics, Regulaxis, Peptinov, 4P Pharma, Paid instructor for: Sandoz, Speakers bureau: Novartis, MSD, Pfizer, Lilly, UCB, Abbvie, Roche, Servier, Sanofi-Aventis, Flexion Therapeutics, Expanscience, GSK, Biogen, Nordic, Sandoz, Regeneron, Gilead, Sandoz, Valentina Vardanyan: None declared, Elena Nikiphorou: None declared, Sebastian C Rodriguez-García Speakers bureau: Novartis Farmaceutica, S.A., Merck Sharp \& Dohme España, S.A., Sanofi Aventis, UCB Pharma, Raul Castellanos-Moreira: None declared, Loreto Carmona Grant/research support from: Novartis Farmaceutica, SA, Pfizer, S.L.U., Merck Sharp \& Dohme España, S.A., Roche Farma, S.A, Sanofi Aventis, AbbVie Spain, S.L.U., and Laboratorios Gebro Pharma, SA (All trhough institution)

DOI: 10.1136/annrheumdis-2020-eular.97

\section{SATURDAY, 06 JUNE 2020 \\ Involvement and innovation in healthcare}

\section{PARE0028 LEAD PATIENTS - A RESOURCE FOR IMPROVEMENT OF THE HEALTH CARE SYSTEM}

\section{Beermann ${ }^{1}$, K. Nilke Nordlund ${ }^{1} .{ }^{1}$ The Swedish National Organization for} Young Rheumatics, Stockholm, Sweden

Background: The project "Lead Patients - a new resource for health", led by researcher Sara Riggare at Karolinska Institutet and financed by Vinnova, the Swedish innovation authority, launched in 2017 and the Swedish National Organization for Young Rheumatics was one out of 14 partners. One of our tasks was to develop training courses for health care staff, and to try out what happens when lead patients are giving the opportunity to educate. We developed and produced nine different courses, and during the Autumn of 2019, we had the chance to try out two of them within the project.

Objectives: The aim was to switch the perspective and see what would happen when patients' expertise and knowledge is used to educate health care professionals and challenge the norm about health care professionals being superior. The objective with first training course, "Teams that enable self-realization", was to create conditions and find new methods for the health care professionals to better support patients with what actually matters to them. The objective with the second training course, "Anti-oppressive pedagogy and language impact," was to create new knowledge as a group and find methods for inclusion and anti-discrimination.

Methods: "Teams that enable self-realization" was conducted as an interactive lecture with a concluding workshop. The lecture was based on results from the Swedish Young Rheumatics Report, teamwork and the Swedish Patient Act. The workshop consisted of a case, where the participants were supposed to come up with a plan for a first meeting and treatment of a patient. "Anti-oppressive pedagogy and language impact" was conducted in two parts, with one week in between the two occasions. The first one was mainly a lecture with background and theory about anti-oppressive pedagogy, norms and power structures, followed by a workshop where the participants analyzed the organizations' own value principals. The second occasion was a deepened discussion with the purpose of identifying new methods for work and strategies to move forward.

Results: The main goal with the training was to highlight positive examples and create creative conditions to be able to identify these new methods and tools. And during the training, there was a great will from the staff to work in a more patient-centered way and let what is most important fort the patient to be what is directing the meeting. Some suggested that the patient should be considered a part of the health care team, but that methods are missing for making it work today. There was also a great will to reflect over what consequences the current health care system might have, and to discuss possible changes. It was exciting to see the traditional hierarchy, where patients are seen as passive receivers of care, being challenged for real and letting patients not only talk about "what it's like to live with a chronic disease" but actually be seen as capable and qualified educators.

Conclusion: If lead patient-led training becomes an obvious and vital part in building and develop the health care system, it will lead to new opportunities and possibilities to better form the health care based on patients' needs, both strategically and operational. Because converting to a patient focused care isn't just about changing old attitudes and organizational culture, it's also about building new adapted structures and methods for governing the health care system.

Disclosure of Interests: None declared

DOI: 10.1136/annrheumdis-2020-eular.3554

\section{PARE0029 THE JOURNEY FROM PATIENT AND PUBLIC ENGAGEMENT (PPE) TO INVOLVEMENT: FACILITATING PATIENT PARTNER RESEARCH WORKSHOPS WITH A FOCUS ON FIBROFOG IN FIBROMYALGIA}

S. Derham ${ }^{1}$, M. Brooke ${ }^{2}{ }^{1}$ Royal United Hospitals Bath NHS Foundation Trust, RNHRD Rheumatology Therapies, Bath, United Kingdom; ${ }^{2}$ Bath Institute for Rheumatic Diseases (BIRD), Patient and Public Engagement (PPE), Bath, United Kingdom

Background: The Bath Institute for Rheumatic Diseases (BIRD), a registered charity in the United Kingdom (UK), supports research, education and patien engagement for the benefit of people with rheumatic diseases. Event feedback from two Fibromyalgia Information Days showed patients valued the sessions and were keen to be involved in research. Fibrofog in fibromyalgia was identified by patients as one topic of interest.

Objectives: To facilitate Patient Research Partner Workshops to generate research questions and inform the design of clinical research into fibrofog in fibromyalgia.

Methods: Three Patient Research Partner Workshops, focusing on fibrofog in fibromyalgia, were run between January 2018 and April 2019. All were co-facilitated by a clinician, SD, and BIRD Patient and Public Engagement (PPE) lead,MB. Ethical approval was not required ${ }^{1}$. Patients were invited to participate by email. A Patient Partner Information Sheet accompanied the workshop invitation. Audio recordings of the discussions were made to aid data capture, following informed written consent by all workshop participants. Travel expenses were offered to all participants.

Results: $25(n=25)$ women with fibromyalgia attended the workshops. Workshop $1(n=5)$ explored, 'What areas do you think we should research around fibrofog in fibromyalgia'? Patient partners felt research into fibrofog in fibromyalgia was needed to identify and validate symptoms, and to inform discussions with healthcare professionals. They also called for research into coping strategies to help with fibrofog symptoms. This reflected similar patient calls for research into fibrofog in fibromyalgia ${ }^{2}$.

Workshop $2(n=10)$ and Workshop $3(n=9)$ explored 'How do you think we should research fibrofog in fibromyalgia'? Both workshops identified a broad range of research questions and designs, reflecting individual experiences, knowledge and symptom severity. Suggested research questions included: How severe is fibrofog for each person? What triggers fibrofog? How does fibrofog affect daily tasks? How does fibrofog affect work? What do people with fibromyalgia their partners, family members and healthcare professionals understand about fibrofog?

Suggested data collection methods included interviews, focus groups and questionnaires. Use of online surveys or interviews had mixed responses. This reflected computer literacy skills and access to hardware. Discussions around recruitment of participants to future studies revealed a wealth of local knowledge including access to community venues and healthcare facilities, support groups and local networks.

Participants were very satisfied with the workshops, finding them helpful, informative and thought provoking. All wanted to continue their involvement in research.

Conclusion: Patient Research Partner Workshops are integral to the generation and delivery of clinical research into fibrofog in fibromyalgia. Research designs need to offer multiple methods of data collection to be as inclusive as possible. Next steps will be to formally recruit Patient Research Partners to co-develop a research grant application to explore fibrofog in fibromyalgia.

References:

[1] INVOLVE. Public involvement in research and research ethics committee review V.2 Southampton: INVOLVE/Health Research Authority; 2016 